\title{
An Experimental Research on Vibration Evaluation of Laminated Hybrid Composite
}

\author{
Y.Seetha Rama Rao, R.Lakshmi, Ch.Siva Ramakrishna, A.Sampath Dakshina Murthy, \\ K.V.SubbaRao
}

\begin{abstract}
Conceptual: the prevailing studies pattern in composite is for the improvement of composite with carbon fiber. it is critical to dissect the vibration conduct of composite for powerful use in severa programs in order that they enjoy with one of a kind styles of stacking situation and exclusive types of vibration with various stacking association of filaments. CFRP has high solidness and slight-weight houses with the intention that their programs had been numerous. in any case, CFRP reviews a immoderate recurrence vibration. on this paper, the impact of basalt fiber hybridization to lessen vibration of carbon fiber pondered via test affiliation. The ends informed that the hybridization of basalt fiber to the carbon fiber and stacking succession have been impressively inspired and diminishes vibration. not unusual recurrence and damping share of half of breed overlaid composites have been received through wearing on exploratory modular research.
\end{abstract}

Watchwords: Hybrid composite, stacking affiliation, regular recurrence studies.

\section{ADVENT}

currently a-days building structures require high concord to weight percentage, excessive safety from disappointment for a advanced exhibition, life span and increment in variety of lifestyles cycles earlier than weak spot crack. So one-of-a-type examines were performed on unfastened vibration response of composite plates with exceptional burdens and fantastic components like temperature, bolster situations, fabric homes and overlay plot. The plates are displayed with stiffeners to have better incredible without growing which means loads.

\section{LITRATURE EVALUATE}

numerous creators utilized extraordinary structures for the beyond numerous years for highlight extraction. This segment will take a look at the strategies used by particular creators. Prasad et al. introduced trial and numerical consequences at the vibration of composite protected plate at diverse restriction situations. A limited detail (FE)- based definitely definition is set up for the plate making use of the essential request Reissner-Mindlin speculation, which incorporates the 2 filaments and metals of severa cloth

Revised Version Manuscript Received on 10, September 2019.

Y.Seetha Rama Rao, Department of Mech Engg, GVP College of Engineering, Visakhapatnam, A.P, India.

R.Lakshmi, Department of Mech Engg,GVP College of Engineering,Visakhapatnam, A.P,India.

Ch.Siva Ramakrishna, Department of Mech Engg,Vignan's Institute of Information Technology,Visakhapatnam, A.P, India.

A.Sampath Dakshina Murthy, Department of ECE Vignan's Institute of Information Technology,Visakhapatnam, A.P, India.

K.V.SubbaRao, Department of Mech Engg,Vignan's Institute of Information Technology,Visakhapatnam, A.P, India. residences in interchange layers [1]. Mishra et al. Displayed a test examination of the feature recurrence of composite Plate. The effect of diverse restrict conditions which includes loose-loose, cantilever, basically upheld, and completely braced end up given and notion approximately results of past examinations in writing any region handy [2],Mohanty et al. contemplated a limited element research for a composite plate with delamination of a woven fiber glass with epoxy [3]. Panda et al. decided the free vibration traits of woven fiber glass/epoxy delaminated doubly bended composite forums in a warm vicinity relying on the restricted thing technique. First-request shear disfigurement speculation is applied for a composite shell version with arrangement of mid-aircraft strip delamination at self-assertive areas. The commonplace frequencies of unfastened vibration of woven fiber composite shells decline with a selection in temperature and delamination area because of lower of solidness for all covers [4]. Faroughi et al. constructed up an iso-geometric approach depending on better request smooth Non-Uniform Rational B-Splines (NURBS) premise capacities for the strain, vibration and electricity examination of overlaid composites. lightweight fabric, as an example, FRP has been widely implemented in aeronautical, maritime, and automobile programs; however, the disadvantage of this framework is that FRPs are defenseless in the direction of impact damage. To defeat those negative factors, an change blend of substances has been utilized (aluminum and FRP). in addition, whilst a composite material is exposed to excessive temperature or adverse condition, it impacts the mechanical and adverse houses. One method to decorate the cloth excellent, even as supplying to this kind of situation, is to cowl every the surfaces of the composite cloth, with a layer of metal cloth [5].

Biswal et al. Explored hygrothermal influences on loose vibration of woven fiber glass/epoxy overlaid composite spherical and hollow shallow shells. numerous analyses are led for spherical and hole shell boards with numerous arch proportions and overlay succession under diverse limit conditions uncovered to uniform distinction in temperature and dampness focuses for examination with FEM outcomes. it's far visible that The not unusual frequencies of loose vibration of included composite shells lessen with increment in uniform temperature and dampness fixation because of decrease of the solidness and increments with diminishing the ebb and glide proportions [6]. 
Chandrashekhar et al. accomplished nonlinear vibration research the usage of a $\mathrm{CO}$ anticipated strain inserted restricted detail plate model dependent on Reddy's 0.33 request speculation. Monte Carlo Simulation with Latin Hypercube Sampling method is implemented to accumulate the difference of direct and nonlinear normal frequencies of the plate due to arbitrariness in its fabric residences. it's miles decided that the nonlinear frequencies display increasing non-Gaussian chance thickness paintings with increasing sufficiency of vibration and display double tops at immoderate abundancy proportions. This disorderly nature of exposed in eigenvalue affectability exam [7]. Madhukar et al. Exhibited a use of the meshfree common neighbor Galerkin method for the static and vibration investigation of plates and covers. The consistency and union of solutions for redirection and stresses had been tested by means of fluctuating request of Gauss quadrature and the quantity of hubs. it's been seen that first-rate combination of results is received with increment in the quadrature focuses and hubs [8].

Dongdong et al. focused unfastened vibration exam of dainty plates making use of Hermite duplicating bit Galerkin art work unfastened method with sub-area balanced out adjusting reconciliation. inside the HRK estimate each the deflectional and rotational degrees of possibility at a traditional area point are considered to boom the bet of the important redirection variable thru all of the whilst forcing the imitating or consistency situations at the diversion and revolutions [9]. Zhou et al. Proposed a replicating piece molecule approach (RKPM) is utilized to break down the commonplace frequencies of Euler-Bernoulli shafts in reality as Kirchhoff plates to foresee the restrained vibration reactions of blanketed pipelines due to longitudinal voyaging waves. two particular techniques, Lagrange multipliers just as exchange approach, are carried out to uphold vital restrict conditions [10].

Rajesh et al. tested banana and sisal fiber arbitrarily organized fortified polymer composite for function recurrence and damping element. impact of numerous weight fee on banana, sisal and half breed composite are contemplated. it's miles decided $1 / 2$ composite has most excessive commonplace recurrence contrasted with exclusive type composites. because it builds the firmness of the cloth. moreover, 1/2 weight composite became treated with sodium hydroxide. The final consequences demonstrates that concoction treatment expands the modulus of the fabric and builds the firmness of the composite [11]. Kumara et al. Analyzed the vibration attributes of bagasse-banana fiber $1 / 2$ of and half composite. The composite is created by way of hand layup tool and its vibration houses are tested wherein vibration check modified into finished by means of the use of opposition pressure sensors to understand the dynamic pressure inside the composite plates [12].

\section{METHOD}

\section{Experimentation}

\section{A. Fabrication of FRP through Hand Lay-Up method}

Basalt fiber and carbon fiber, epoxy gum (LY556) and hardener (HY951) are implemented for trial work. The fiber masses have been sliced to degree from the fiber cloth. Epoxy the scattering of nonlinear eigenvalues is additionally

and hardener are taken in the proportion 10:1 and that they were mixed. whilst blending preserve a strategic distance from the association of air pockets. since the air wallet had been displayed in community have to result sadness within the composite. the following level comprised of placing smooth film at the shape floor. next a chateau wax smooth became applied at the sheets. At that element fiber address of one type changed into positioned and exercise epoxy pitch combination. Rehash with required fiber grouping and rolled. Rolling have become completed utilising metal bar. On the very best thing of the ultimate utilize a wax masking is accomplished which serves to assure a divine being ground completion. At prolonged final, a discharging sheet became put on the pinnacle and a slight rolling modified into performed. It emerge as left for 48 hrs to allow appropriate enough time for restoring and resulting solidifying.

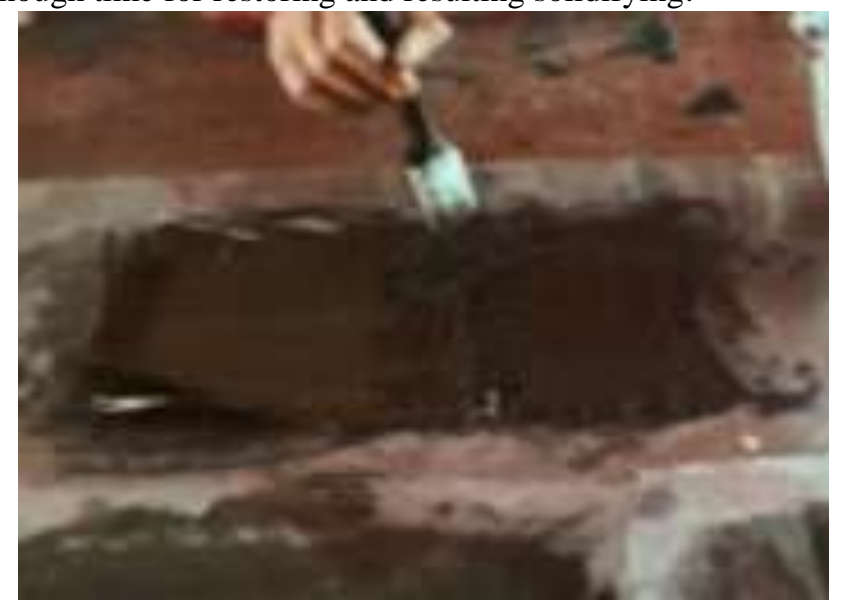

Fig. 1 Fabrication of fiber overlay

\section{B. preparation of test examples}

The composite examples had been reduce into $200 \mathrm{~mm} \times$ $20 \mathrm{~mm}$ with the aid of making use of a dance observed device for trial modular finding out. The suggest thickness of fiber covers grow to be assessed thru superior sliding calipers and saw as $2 \mathrm{~mm}$.

\section{Vibration check association}

A check arrangement, made out of a universally useful PCB 352C33 earthenware shear ICP accelerometer, a PCB 086C02 broadly beneficial modular effect hammer, and an facts procurement device with LABVIEW programming, was applied to decide the recurrence of the created composite substances. The examples as a cantilever shaft had been energized with the impact hammer most of the braced district and the accelerometer location. The impact excitations have been done on 5 examples of each overlay format and rehashed in any event a couple of times for every instance. To maintain time-subordinate growing velocity response of the instance, the accelerometer and the mallet had been related to a laptop via the facts procurement device and treated with LABVIEW programming. The time subordinate increasing speed response became then modified into recurrence area with the help of brief Fourier trade and used to assess the recurrence reaction capacities (FRFs). The half 
of-manipulate statistics switch potential method, in mild of discovering transmission potential of the recurrence reaction sufficiency for each mode, become applied to assess the damping coefficient estimations of composite covers. In facts, the damping esteems for the number one mode had been determined the use of the accompanying connection

$$
\xi=\frac{\Delta \omega}{2 \omega_{n}}
$$

Where $\xi$ is damping ratio, $\Delta \omega$ is bandwidth, and $\omega_{n}$ is natural frequency of the second mode.

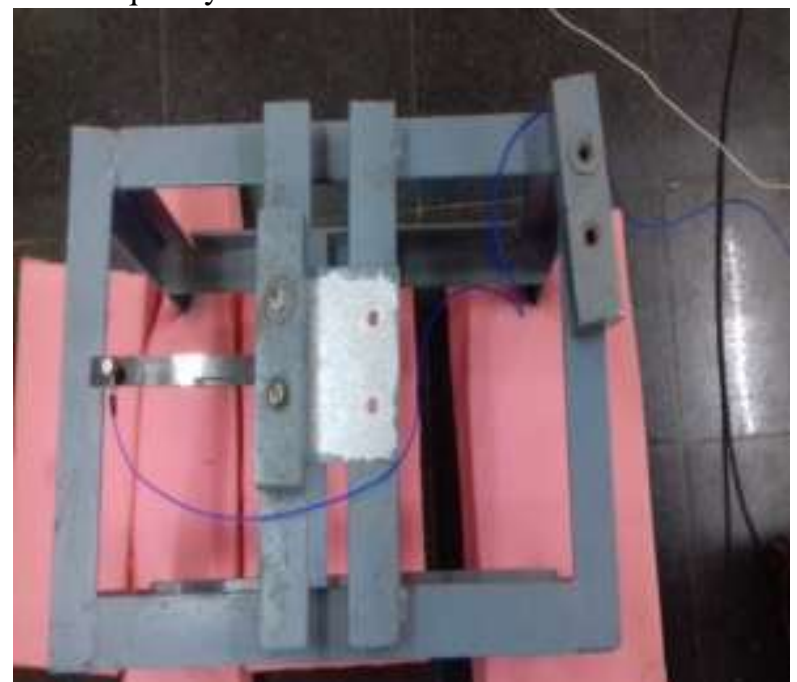

Fig. 2 Vibration test of composite with clamped boundary condition.

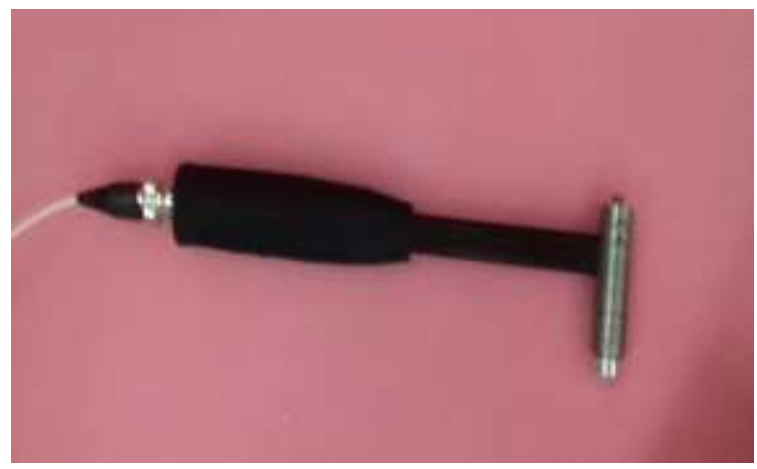

Fig. 3 Modal impact hammer

The impact hammer is connected to channel 1 and the accelerometer is connected to channel 2 of data acquisition device.

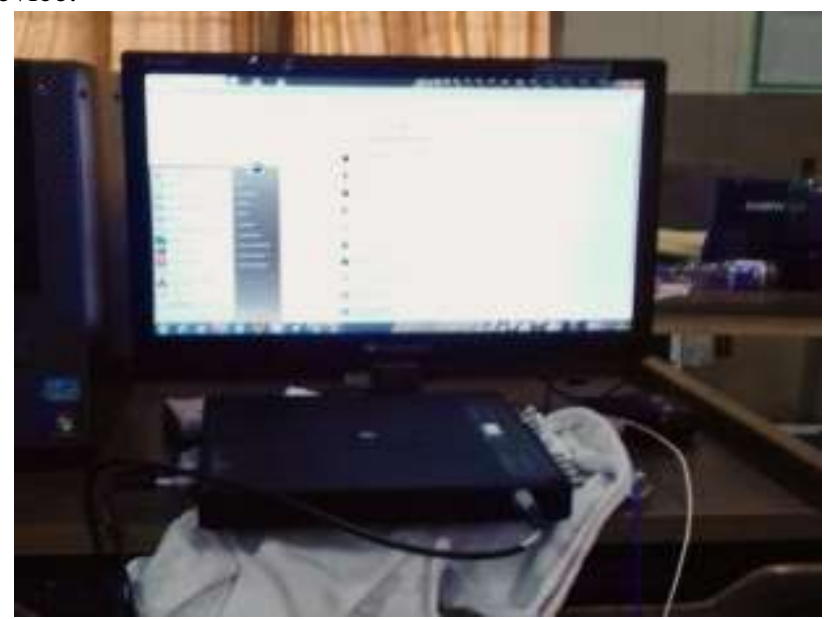

Fig. 4 show unit and channel institutions.

\section{RESULT EVALUATION}

The research portrayal is introduced on vibration exam of overlaid pass breed composite underneath.

\section{A. Vibration evaluation}

The FRF bend created thru LABVIEW programming as the outcome of loose vibration trial of $1 / 2$ breed and non-aggregate covers are given in Fig.5. The recurrence reaction attributes of covers is based upon the homes and stacking association of materials. common frequencies are displayed in desk 1 . The results display that each single $1 / 2$ of breed cover have less ordinary recurrence close to to non-go breed CFRP covers. The reductions in normal recurrence are sixteen.6\%, $41.4 \%$ and $10.37 \%$ for CBCB, BCCB and CBBC $1 / 2$ of breed covers, individually. In each single half of and half of overlay, the BCCB cover show the bottom everyday recurrence this is $158 \mathrm{~Hz}$.

\begin{tabular}{|l|l|l|}
\hline $\begin{array}{l}\text { Stacking } \\
\text { sequence }\end{array}$ & $\begin{array}{l}\text { Natural frequency } \\
\text { (Hz) }\end{array}$ & $\begin{array}{l}\text { Damping } \\
\text { ratio }\end{array}$ \\
\hline CCCC & 270 & 0.0129 \\
\hline BBBB & 160 & 0.025 \\
\hline CBCB & 225 & 0.013 \\
\hline BCCB & 158 & 0.028 \\
\hline CBBC & 242 & 0.014 \\
\hline
\end{tabular}

Table 1 Second mode of natural frequency of hybrid and non-hybrid laminates.

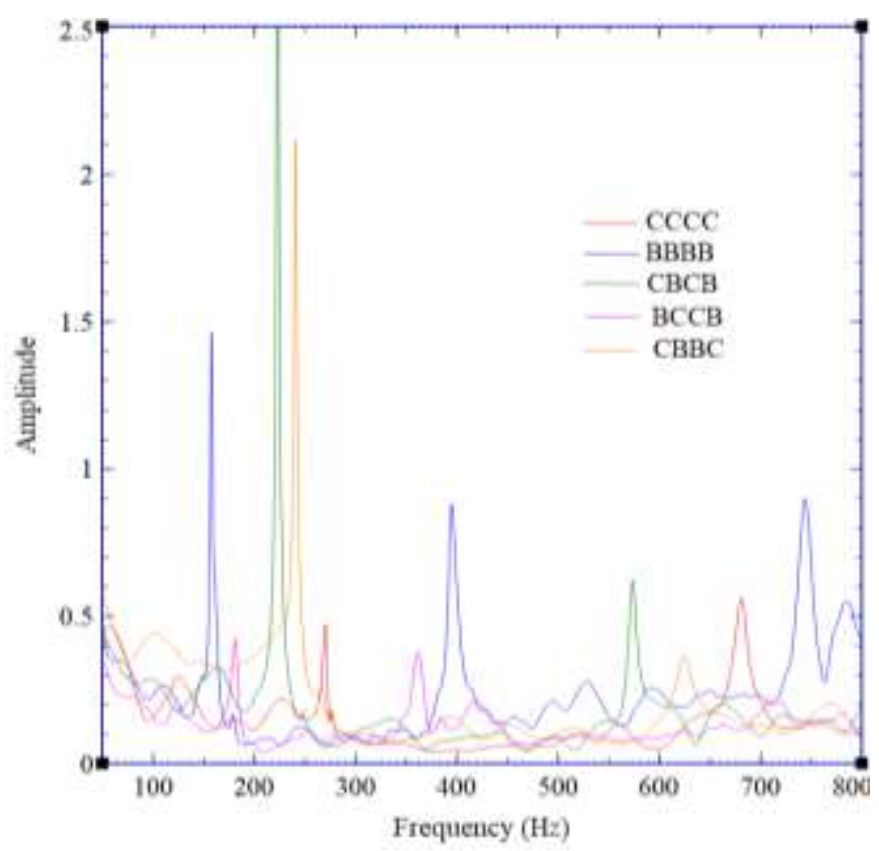

Fig. 5 Frequency response curves of hybrid and non-hybrid laminates.

Damping percent of all overlays had been resolved from FRF bends utilizing half of-control records transmission approach at second mode. The BCCB overlay having immoderate damping proportion 0.028 . 


\section{CONCLUSION AND FUTURE SCOPE OF WORK}

on this investigation, modular exam became achieved tentatively for overlaid cantilever composites to expect the everyday frequencies. The impact of hybridization and severa cowl stacking succession changed into likewise examined. The ends are abridged as pursues: The carbon-basalt fortified epoxy half of and half composites are effectively created making use of hand lay-up technique. The BCCB overlay having least ordinary recurrence $158 \mathrm{~Hz}$ and excessive damping percentage contrasted with super covers.

The present exam has been completed making use of easy hand lay-up method. in any case, the exploration paintings may be extended further through manner of considering wonderful strategies for composite introduction and the impact of assembling structures at the presentation of composites can comparably be examined and can be broadened in addition by way of the development of $1 / 2$ breed composites making use of tough particulate fillers alongside CFRP and Basalt filaments and the exam also can be broke down.

\section{REFERENCES}

1 Prasad, E. V., and S. okay. Sahu. "Vibration analysis of Woven Fiber steel Laminated Plates-Experimental and Numerical research." international magazine of Structural stability and Dynamics: 1850144.

2 Mishra, Itishree, and Shishir Kumar Sahu. "Modular investigation of woven fiber composite plates with various restrict conditions." worldwide journal of Structural stability and Dynamics 15, no. 01 (2015): 1540001.

3 Mohanty, J., S. ok. Sahu, and P. ok. Parhi. "Numerical and exploratory examination on unfastened vibration of delaminated woven fiber glass/epoxy composite plates." global journal of Structural stability and Dynamics 12, no. 02 (2012): 377-394.

4 Panda, Himanshu Sekhar, Shishir Kumar Sahu, Pravat Kumar Parhi, and Avittathur Venkiteswaran Asha. "Vibration of woven fiber composite doubly bended forums with strip delamination in warmness subject." journal of Vibration and manage 21, no. 15 (2015): 3072-3089.

5 Faroughi, S., E. Shafei, and D. Schillinger. "Isogeometric stress, vibration and strength exam of in-plane covered composite structures." international magazine of Structural stability and Dynamics 18, no. 05 (2018): 1850070.

6 Biswal, M., S. okay. Sahu, and A. V. Asha. "Vibration of composite spherical and hole shallow shells exposed to hygrothermal stacking trial and numerical consequences." Composites element B: Engineering 98 (2016): 108-119.

7 Chandrashekhar, M., and Ranjan Ganguli. "Nonlinear vibration examination of composite protected and sandwich plates with atypical cloth houses." global magazine of Mechanical Sciences fifty two, no. 7 (2010): 874-891.

8 Somireddy, Madhukar, and Amirtham Rajagopal. "Meshless everyday neighbor Galerkin technique for the twisting and vibration examination of composite plates." Composite Structures111 (2014): 138-146.

9 Wang, Dongdong, and Zhenting Lin. "free vibration research of slim plates using Hermite repeating piece Galerkin meshfree technique with sub-area settled accommodating mixture." Computational Mechanics 46, no. five (2010): 703-719.

10 Zhou, J. X., H. Y. Zhang, and L. Zhang. "Imitating detail molecule method for now not some thing and confined vibration research." journal of sound and vibration 279 , no. 1-2 (2005): 389-402.

11 Rajesh, M., Jeyaraj Pitchaimani, and N. Rajini. "unfastened vibration tendencies of banana/sisal commonplace filaments strengthened half breed polymer composite shaft." Procedia Engineering a hundred and forty 4 (2016): 1055-1059.

12 Vas, John Paul, Shreeranga Bhat, and Karthik Madhyastha. "A have a look at at the Vibration traits of Bagasse-Banana Fiber Hybrid Composite." worldwide journal of Composite substances 7, no. 5 (2017): a hundred and fifty-154. 